\title{
Removal of biological organics in high-salinity wastewater produced from methylcellulose production and subsequent changes in the microbial community
}

\author{
GueSoo Jo ${ }^{1}$, SeongWan Hong, ${ }^{1,2}$ HyunGu Kim², Zhuliping ${ }^{3}$, DaeHee Ahn ${ }^{1,2,+}$ \\ ${ }^{1}$ Department of Environmental Engineering and Energy, Myongji University, Yongin 17058, Republic of Korea \\ ${ }^{2}$ BlueBank Co., Ltd., Business Incubator Center, Myongji University, Yongin 17058, Republic of Korea \\ ${ }^{3}$ Wuxi YDS Environmental Protection \& Energy Saving Co., Ltd., Environmental Protection Technology Building, Yixing 214200, P.R. China
}

\begin{abstract}
The wastewater generated in methylcellulose $(\mathrm{MC})$ production is characterized by high salinity and $\mathrm{pH}$ due to the residual sodium and chlorine separated from the methyl group. It is difficult to treat wastewater using the conventional activated sludge method because the high concentration of salt interferes with the microbial activity. This study confirms the biological removal of organic matter from MC wastewater using sludge dominated by Halomonas spp., a halophilic microorganism. The influent was mixed with MC wastewater and epichlorohydrin (ECH) wastewater in a 1:9 ratio and operated using a sequencing batch reactor with a hydraulic retention time of $27.8 \mathrm{~d}$ based on the MC wastewater. The removal efficiency of chemical oxygen demand (COD) increased from $80.4 \%$ to $93.5 \%$, and removal efficiency had improved by adding nutrients such as nitrogen and phosphorus to the wastewater. In terms of microbial community change, Halomonas spp. decreased from $43.26 \%$ to $0.11 \%$, whereas Marinobacter spp. and Methylophaga spp. increased from $0.50 \%$ to $15.12 \%$ and $7.51 \%$, respectively.
\end{abstract}

Keywords: Biological treatment, High salinity wastewater, Methylcellulose, Microbial community, Pyrosequencing

\section{Introduction}

Although cellulose is a widely used natural polymer material, its use is limited due to its low solubility. Cellulose derivatives have been studied to address this issue and expand the scope of applications. In particular, methylcellulose (MC) is a cellulose derivative that resolves the insoluble properties of cellulose in organic and inorganic solvents, and has recently been used in diverse industrial applications such as food, petrochemicals, and building materials [1-3].

MC wastewater is characterized by high levels of salinity and organic matter. During MC production, chloride ions are separated from chloromethane and sodium ions separated from sodium hydroxide are discharged as wastewater $[4,5]$. In addition, MC production involves the addition of a plasticizer (propylene glycol) and solvent (1-methoxy-2-propanol) [6], and the chemical oxygen demand (COD) concentration in the wastewater is increased by residual plasticizers and solvents.

High concentrations of salt affect biological activity in the conventional activated sludge process [7], in which microorganisms have a high osmotic pressure in their cells. High osmotic pressure can lead to the dehydration and degradation of cells and inhibit the growth and activity of microorganisms [8]. However, halophiles are known to dominate highly saline conditions and have the capacity to remove organic compounds without inhibition [9-13].

Although research on MC wastewater treatment has confirmed the potential to substitute an external carbon source necessary for denitrification [14], there is insufficient research compared to other cellulose-based wastewaters. A study on carboxymethyl cellulose (CMC) wastewater treatment, a cellulose ether (carboxy alkyl series) similar to MC, was conducted using a physicochemical treatment method $[15,16]$ and a physicochemical-biological mixing method [17, 18]. Although these studies demonstrated effective organic matter removal, each of the physicochemical treatments
This is an Open Access article distributed under the terms of the Creative Commons Attribution Non-Commercial License (http://creativecommons.org/licenses/by-nc/3.0/) which permits unrestricted non-commercial use, distribution, and reproduction in any medium, provided the original work is properly cited.

Copyright (C) 2021 Korean Society of Environmental Engineers
Received April 20, 2020 Accepted September 09, 2020

${ }^{\dagger}$ Corresponding author

Email: dhahn@mju.ac.kr

Tel: +82-31-321-5901 Fax: +82-505-300-5901

ORCID: 0000-0002-6031-3610 
used had the disadvantage of high energy consumption [16, 19]

Petrochemical and food processing wastewaters are similar to MC wastewater with high salt and organic content [20, 21]. High-salt wastewater is treated in parallel with physical and chemical treatments [20, 22, 23], at great expense and energy expenditure [7]. Although studies using anaerobic sequencing batch biofilm reactors (AnSBBR) and membrane bioreactors (MBR) require lower cost and energy consumption compared to physicochemical treatments [24, 21], extracellular polymeric substances (EPS) released by microorganisms at high salt concentrations exhibit sub-optimal performance of the membrane (biofilm and membrane) [25, 26].

Other studies have applied several physicochemical methods such as cohesion, distillation, photocatalysts, and membranes [1518, 20, 22-24]. However, there has been an absence of studies demonstrating the removal of COD from MC wastewater using biological methods. The purpose of this study was to remove the COD of MC wastewater through a biological method under highly saline conditions using sludge dominated by halophiles. In this study, we aimed to identify the microbial community changes through pyrosequencing and provide useful insights into MC wastewater treatment.

\section{Material and Methods}

\subsection{Properties and Characteristics of the Wastewater}

The wastewater used in the study was actual wastewater generated during $\mathrm{MC}$ and $\mathrm{ECH}$ manufacturing processes. MC wastewater has a high organic matter load of 40,000-60,000 mg/L COD; and its properties are shown in Table 1 [14]. In this study's preliminary experiments, a foaming problem occurred when MC wastewater was independently treated. The method of mixing ECH wastewater was found to resolve this foaming problem. The ECH wastewater is wastewater from other processes generated during MC manufacturing and has lower salinity and COD concentrations than MC wastewater. The ECH wastewater is characterized by a COD of 150-1,500 mg/L, total nitrogen (TN) N.D., total phosphorus (TP) N.D., and an $\mathrm{NaCl}$ concentration of $2,000 \mathrm{mg} / \mathrm{L}$.

Table 1. The Compounds of MC Wastewater

\begin{tabular}{lc}
\hline Compound & Composition(wt\%) \\
\hline Methanol & 30 \\
Propylene glycol & 30 \\
1-methyloxy-2-propanol & 30 \\
NaCl & 12 \\
\hline
\end{tabular}

\subsection{Reactor and Experimental Setup}

In this study, a laboratory-scale sequencing batch reactor (SBR) with a $5 \mathrm{~L}$ effective volume (length: $155 \mathrm{~mm}$, width: $155 \mathrm{~mm}$, height: $222 \mathrm{~mm}$ ) was used (Fig. S1). The initial mixed liquor suspended solids (MLSS) concentration was $6,000 \mathrm{mg} / \mathrm{L}$ and the seed sludge was dominated by Halomonas spp.. The influent used was a mixture of $\mathrm{MC}$ and $\mathrm{ECH}$ wastewater, mixed at a ratio of 1 to
9, respectively. The SBR operation consisted of one cycle per day under aerobic conditions, and air was introduced by an air diffuser at the bottom of the reactor with a $2 \mathrm{~L} / \mathrm{min}$ aeration flow rate. The SBR cycle times were controlled using a programable logic controller (PLC), and each cycle lasted for, with a feeding of $10 \mathrm{~min}$ aeration of $23 \mathrm{~h}$ and $10 \mathrm{~min}$, settling of $30 \mathrm{~min}$, and a decanting time of $10 \mathrm{~min}$. The total operation period was 108 $\mathrm{d}$, and the hydraulic retention time (HRT) was $2.78 \mathrm{~d}$ (exchange rate $36 \%)$.

In the initial operation, organic matter removal occurred without the addition of phosphorus and nitrogen. The removal efficiency in this study was less than $80 \%$ as the wastewater was nutrient-deficient and required for the biological reaction. To increase removal efficiency, nutrients were administered as shown in Table 2 after $53^{\text {rd }}$ day. The nutrients were used in the following reagents; the nitrogen source being ammonium chloride $\left(\mathrm{NH}_{4} \mathrm{Cl}\right.$, SAMCHUN Chemical, Korea), and the phosphorus source being potassium phosphate $\left(\mathrm{KH}_{2} \mathrm{PO}_{4}\right.$, SAMCHUN Chemical, Korea).

Table 2. The Change of Condition by Operating Period

\begin{tabular}{lccc}
\hline & $\begin{array}{c}\text { Operation time } \\
(\mathbf{d})\end{array}$ & $\begin{array}{c}\mathbf{N H}_{4}{ }^{+}-\mathbf{N} \\
(\mathbf{m g} / \mathbf{L})\end{array}$ & $\begin{array}{c}\mathbf{P O}_{4}{ }^{-3}-\mathbf{P} \\
(\mathbf{m g} / \mathbf{L})\end{array}$ \\
\hline Phase 1 & $0-53$ & - & - \\
Phase 2 & $54-56$ & 75 & 15 \\
Phase 3 & $57-60$ & 35.5 & 7.5 \\
Phase 4 & $61-80$ & 18.75 & 7.5 \\
Phase 5 & $81-108$ & 10 & 7.5 \\
\hline
\end{tabular}

\subsection{Analysis of Microbial Community}

Changes in the microbial community were observed by pyrosequencing analysis, carried out using the initial and end phases. The supernatant was removed after centrifugation, and deoxyribonucleic acid (DNA) was extracted using the FastDNA SPIN Kit for soil (MP Biomedicals). The polymerase chain reaction (PCR) (C1000 Touch thermal cycler, Bio-Rad) used $2 \mu \mathrm{L}$ of extracted DNA and proceeded with the primary amplicon and secondary index. In the primary PCR amplicon, the initial denaturation was performed at $95^{\circ} \mathrm{C}$ for $3 \mathrm{~min}$. After 25 cycles of denaturation $\left(95^{\circ} \mathrm{C}\right.$, $30 \mathrm{~s}$ ), the annealing $\left(55^{\circ} \mathrm{C}, 30 \mathrm{~s}\right)$, extension $\left(72^{\circ} \mathrm{C}, 30 \mathrm{~s}\right)$, and final extension $\left(72^{\circ} \mathrm{C}, 5 \mathrm{~min}\right)$ was conducted and finally fixed at $4^{\circ} \mathrm{C}$. In the secondary index PCR, initial denaturation was performed at $95^{\circ} \mathrm{C}$ for $3 \mathrm{~min}$. After 8 cycles of denaturation $\left(95^{\circ} \mathrm{C}, 30 \mathrm{sec}\right)$, annealing $\left(55^{\circ} \mathrm{C}, 30 \mathrm{~s}\right)$, extension $\left(72^{\circ} \mathrm{C}, 30 \mathrm{~s}\right)$, final extension $\left(72^{\circ} \mathrm{C}\right.$ $5 \mathrm{~min}$ ) was performed and finally fixed at $4^{\circ} \mathrm{C}$. Illumina MiSeq was used for DNA sequencing, and the obtained nucleotide sequence was subsequently analyzed using CLcommunity ${ }^{\mathrm{TM}}$ (Chunlab Inc., Seoul, Korea). [27, 28].

\subsection{Water Quality Analysis}

Water quality analysis was performed with a filtrate using a glass fiber filter (GF/C). In addition, $\mathrm{COD}, \mathrm{NH}_{4}{ }^{+}-\mathrm{N}, \mathrm{PO}_{4}{ }^{-3}-\mathrm{P}$, and MLSS were analyzed according to the standard method [29]. The shape of the sludge was observed at $40 \times$ magnification using an optical microscope (OLYMPUS CX31). 


\section{Results and Discussion}

\subsection{Biological COD Removal}

Fig. 1 presents the concentration profiles and the COD removal efficiency in Phase 1. The average COD concentrations of the influent and effluent was 4,400 and 1,300 mg/L, respectively. Removal efficiency was up to $80 \%$ over a period of approximately $50 \mathrm{~d}$ without the addition of nutrients. Studies of complex chemical wastewater treatment with similar properties obtained a removal efficiency of $50 \%$ and 51\% [24, 30]. Although Qin et al. [21] confirmed a removal efficiency of $77 \%$ of organic matter in the salt $(30,000 \mathrm{mg} \mathrm{NaCl} / \mathrm{L})$ higher than in this study $(13,800 \mathrm{mg} \mathrm{NaCl} / \mathrm{L})$, we confirmed a relatively high removal efficiency even in a nutrient-deficient state.

Nitrogen, phosphorus, and external carbon sources should be added because industrial wastewater may lack the nutrients necessary for biological treatment [31]. The ratio of carbon (C) to nitrogen (N) to phosphorus (P) in biological treatment is known to be 100:5:1 [32]. However, the MC wastewater contained no nutrient salts other than the organic compounds, thus the change in COD removal efficiency was confirmed by adding deficiency nutrients (i.e., nitrogen and phosphorus).

Fig. 2 presents the concentration changes in COD, nitrogen, and phosphorus during the operation period. Following nutrient injection, the accumulation of nitrogen and phosphorus occurred because of the excessive nutrients required by microorganisms. As such, the injection of nitrogen and phosphorus in Phase 3 was reduced to half that of Phase 2. In Phase 4, nitrogen injection was reduced to half that of Phase 3, but the accumulation of nitrogen was confirmed. In the next phase, nitrogen had not increased as nitrogen injection had reduced to half of Phase 4 .

Ammary [33] showed that the C:N:P ratio was 113:3.3:1 in a similar wastewater treatment study using biological treatment, and the removal efficiency of organic compounds was $75 \%$. In this study, the maximum efficiency in Phase 1 was $80.4 \%$, and increased up to $93.5 \%$ through nutrient injection after Phase 2. At that time, the C:N:P ratio was 240:1.3:1 (Phase 5). This indicates that the removal of high concentrations of organic matter may be achieved through the injection of appropriate nutrients.

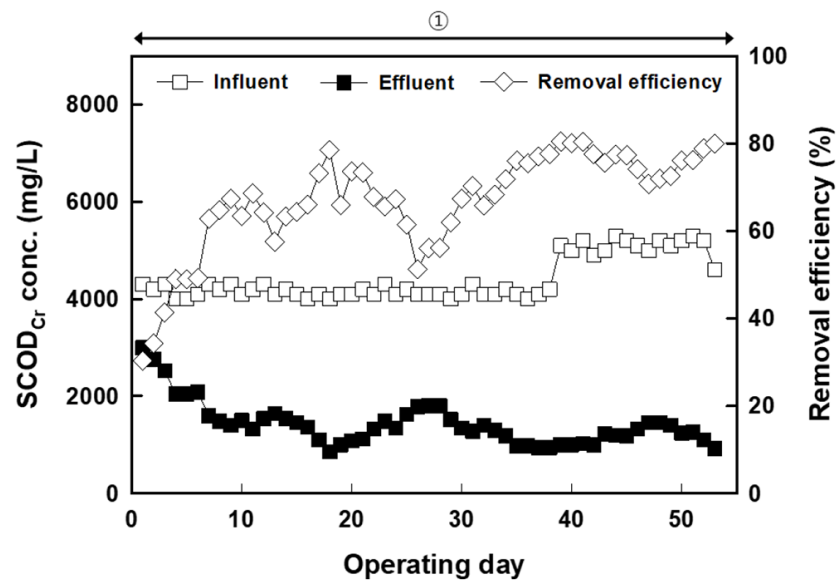

Fig. 1. The profiles of $\mathrm{SCOD}_{\mathrm{Cr}}$ concentration and removal efficiency in phase 1.
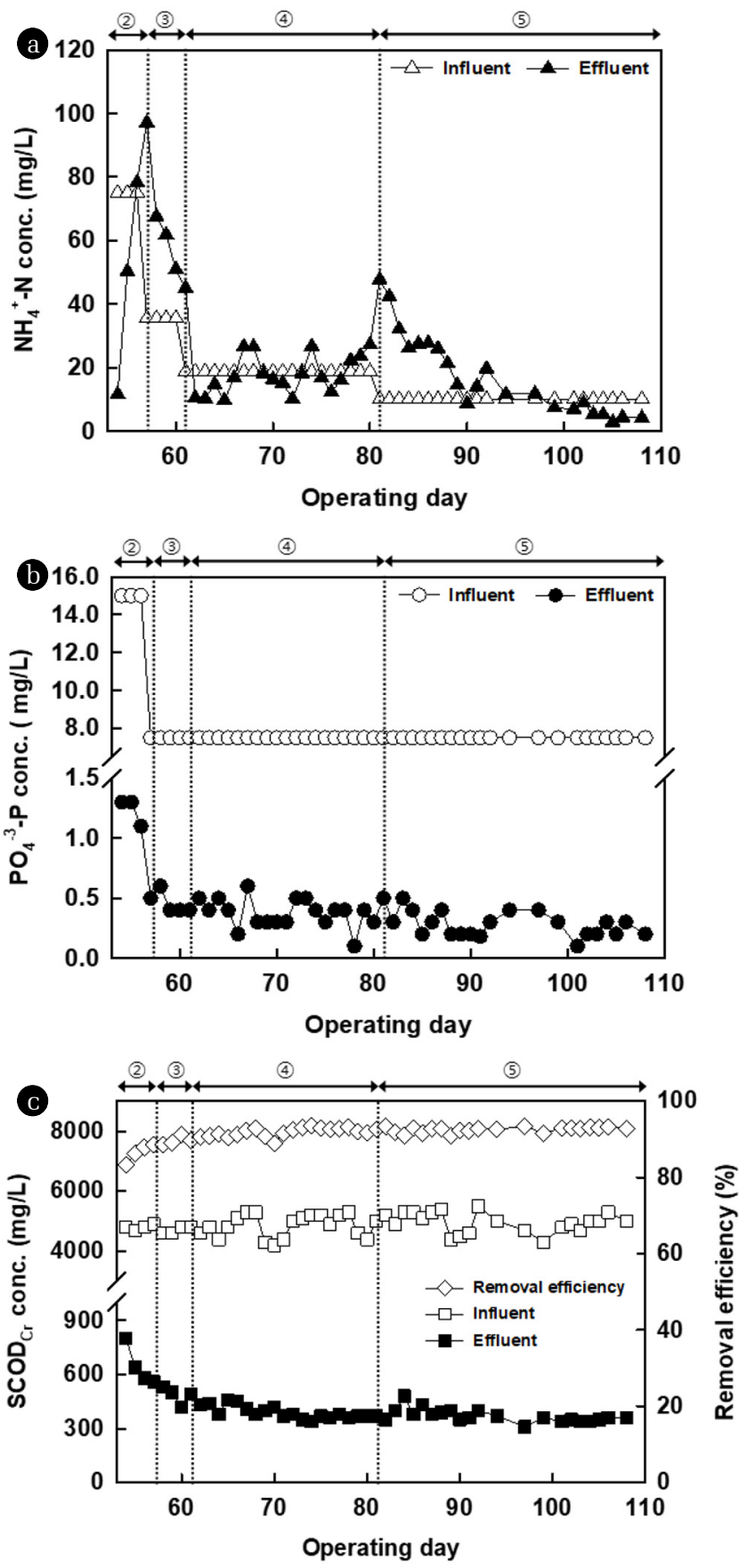

Fig. 2. The profiles of $\mathrm{NH}_{4}{ }^{+}-\mathrm{N}$, (a), $\mathrm{PO}_{4}^{-3}-\mathrm{P}$, (b), $\mathrm{SCOD}_{\mathrm{G}}$, (c) concentration and removal efficiency according to operating condition change (2): phase 2, (3): phase 3, (4): phase 4, (5): phase 5).

\subsection{MLSS and Sludge Morphology}

Fig. 3 shows the change in MLSS and COD removal efficiency. The MLSS concentration increased from $6,000 \mathrm{mg} / \mathrm{L}$ to approximately $12,000 \mathrm{mg} / \mathrm{L}$ during Phase 1 . During Phases 2 to 4 , the MLSS concentration gradually increased to $18,000 \mathrm{mg} / \mathrm{L}$. In Phase 5 , agitation by aeration was difficult because of the high MLSS 


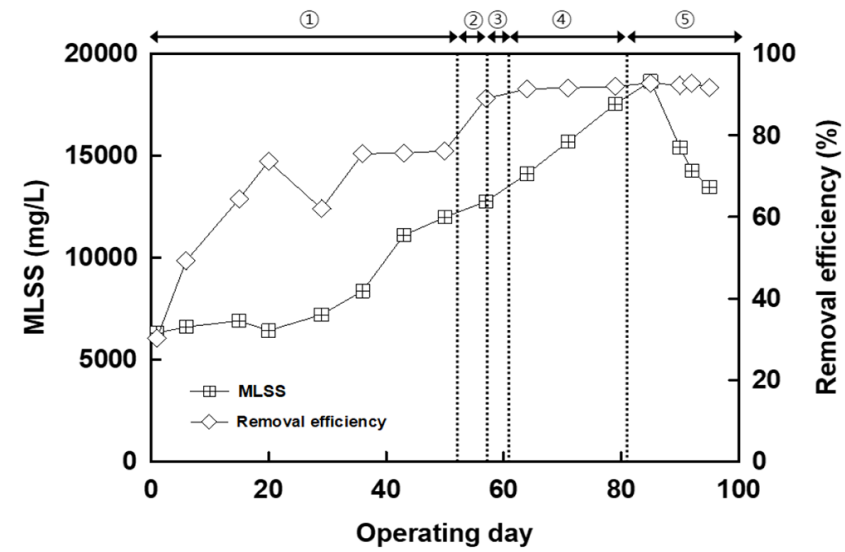

Fig. 3. The profiles of MLSS concentration and SCODCr removal efficiency. concentration, and sludge washout occurred during the effluent (96 d). At that time, the sludge in the reactor had a high proportion of filamentous (Fig. 4(i)), and the suspended solids (SS) of the effluent increased, resulting in a decrease to MLSS to approximately $13,500 \mathrm{mg} / \mathrm{L}$.

Studies using biological treatment processes (industrial wastewater: COD 1,000-1,800 mg/L) demonstrate an increase in MLSS of approximately 3,000 mg/L after 2 and 4 months [34, 35]. The results of a study on municipal wastewater (biochemical oxygen demand $\left(\mathrm{BOD}_{5}\right) 100 \mathrm{mg} / \mathrm{L}$ ) confirmed an MLSS increase of approximately 2,000 mg/L after 12 months [36]. However, this study observed a large increase in MLSS, attributed to the higher COD concentration $(4,600 \mathrm{mg} / \mathrm{L})$ compared to other studies.

Fig. 4 shows the sludge morphology observed with an optical microscope during the operation period. The sludge was observed to exhibit a granular morphology after the $30^{\text {th }}$ day. The formation
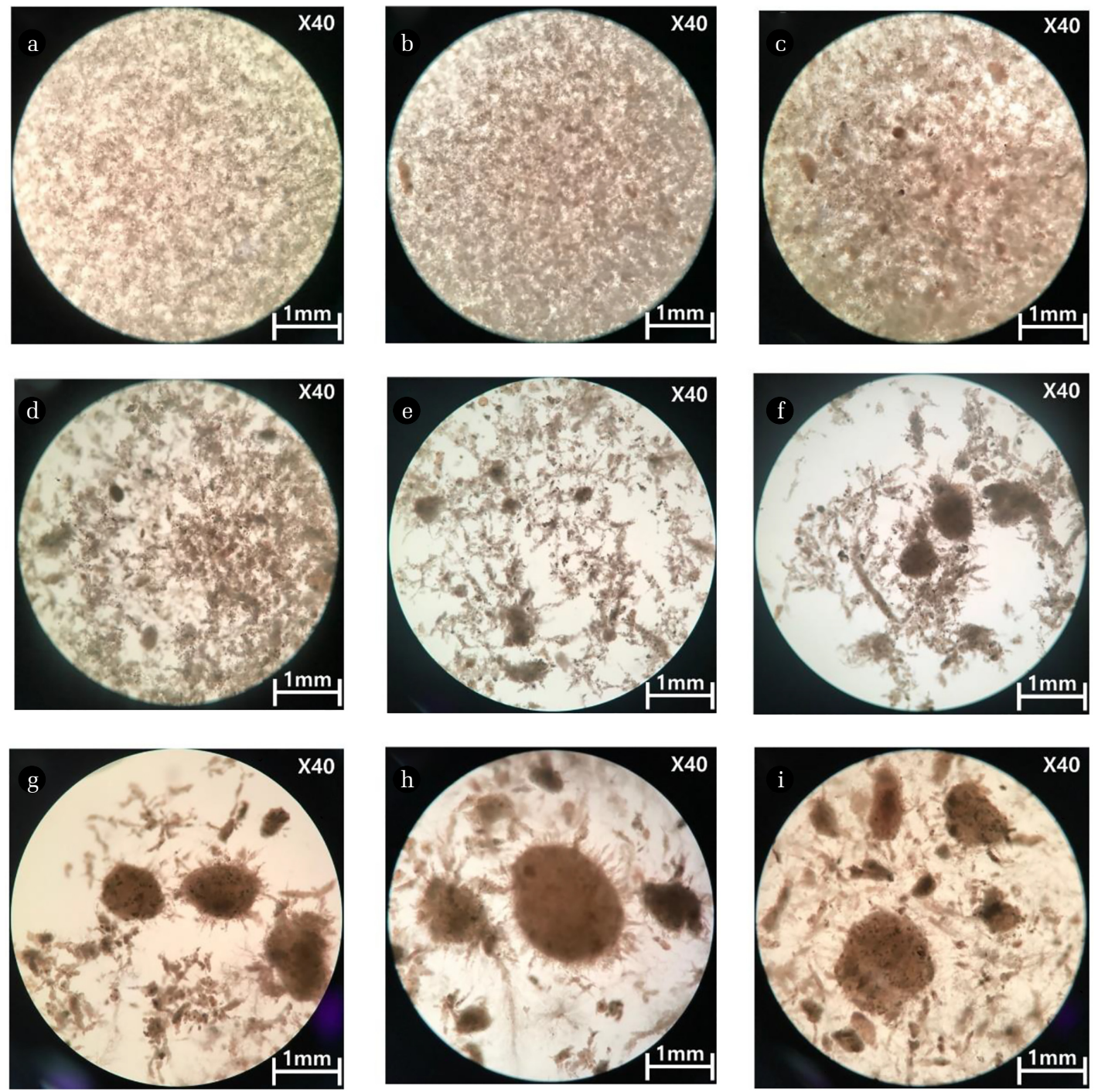

Fig. 4. Morphology observation of sludge during the operation((a): $3 \mathrm{~d}$, (b): $10 \mathrm{~d},(\mathrm{c}): 20 \mathrm{~d},(\mathrm{~d}): 31 \mathrm{~d},(\mathrm{e}): 38 \mathrm{~d},(\mathrm{f}): 45 \mathrm{~d},(\mathrm{~g}): 62 \mathrm{~d},(\mathrm{~h}): 73 \mathrm{~d}$, (i): $97 \mathrm{~d}$ (X40 magnification by optical microscope)). 
of extracellular polymer substances (EPS) by bacteria is known to increase with osmotic pressure with a rise in the salt concentrations of the wastewater [37]. EPS plays an important role in the formation and stabilization of granules by combining bacteria [38, 39]. In addition, $\mathrm{Ca}^{+2}$ is able to bind to negatively charged groups of bacterial surfaces and EPS and act as a bridge to interconnect these components [40], enabling the replacement of $\mathrm{Ca}^{+2}$ by $\mathrm{Na}^{+}$in highly saline wastewater [41].

The salt concentration of MC+ECH wastewater was 13,800 mg/L, higher than that of other wastewaters. In this study, we confirmed the formation of granular sludge over $1 \mathrm{~mm}$, and the saline condition was favorable for the formation of aerobic granular sludge [42]. In addition, granular sludge formation based on salt condition changes confirmed that an average of $4 \mathrm{~mm}$ of granular sludge had formed in salt condition of 40,000 mg/L [43]. Fig. 4(g)-(i) shows that the sludge had a complete granular morphology after the $50^{\text {th }}$ day.

\subsection{Microbial Community Analysis}

Fig. 5 illustrates the change in the microbial community based on phylum ((a): initial, (b): end). In the Proteobacteria of the great population proportion, (a) and (b) were 59.23\% and $40.30 \%$, respectively. In general, Betaproteobacteria in Proteobacteria dominate the microbial community of wastewater treatment systems [44]. However, in this study, the Proteobacteria was dominated by Gammaproteobacteria. The majority of Gammaproteobacteria identified in the study were halophilic microorganisms, in which Gammaproteobacteria dominated saline wastewater treatment systems [45]. The reduction proportion (22\%) of Gammaproteobacteria was similar to that of Proteobacteria (19\%), which indicates large-scale changes in other halophilic species or phylum (e.g., Chloroflexi, Bacteroidetes, and Actinobacteria).

The dominant phylum in the microbial community changed from Bacteroidetes to Chloroflexi, Actinobacteria etc.. Chloroflexi and Actinobacteria constituted a low proportion of the microbial community at $0.36 \%$ and $0.54 \%$ in (a), and increased significantly to $26.24 \%$ and $16.63 \%$ in (b), respectively. Chloroflexi and Actinobacteria belong to filamentous bacteria such as Caldilineaceae and Nocardiaceae, respectively [46, 47]. Filamentous bacteria are known to physically induce binding between bacteria to provide the necessary attraction in the early stages of granulation [48]. Although Chlorobi was not present in (a), it was present at $4.62 \%$ in (b). Some microorganisms belonging to the Chlorobi phylum have thermophilic characteristics and are able to decompose compounds such as phthalate esters [49]. The proportion of Rhodothermaeota increased from $2.83 \%$ in (a) to $4.02 \%$ in (b). It is known that microorganisms belonging to Rhodothermaeota possess thermophilic characteristics and mainly grow in a saline environments similar to seashores [50, 51]. The increase in thermophilic microorganisms is expected to be related to the operating temperature used in this study. The temperature of the discharged MC wastewater was greater than $75^{\circ} \mathrm{C}$, and the temperature of the reactor in the actual wastewater treatment plant was approximately $40^{\circ} \mathrm{C}$. In our study, it was estimated that an increased proportion of thermophilic microorganisms (e.g., Chlorobi and Rhodothermaeota) was possible as the operating temperature was approximately $35-40^{\circ} \mathrm{C}$.

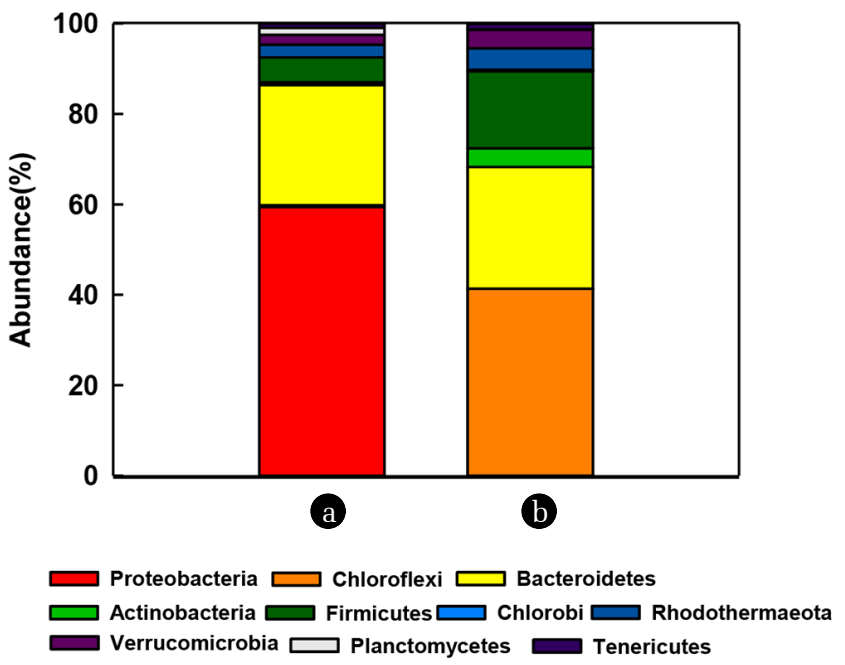

Fig. 5. Bacterial compositions at the phylum level((a): initial, (b): end).

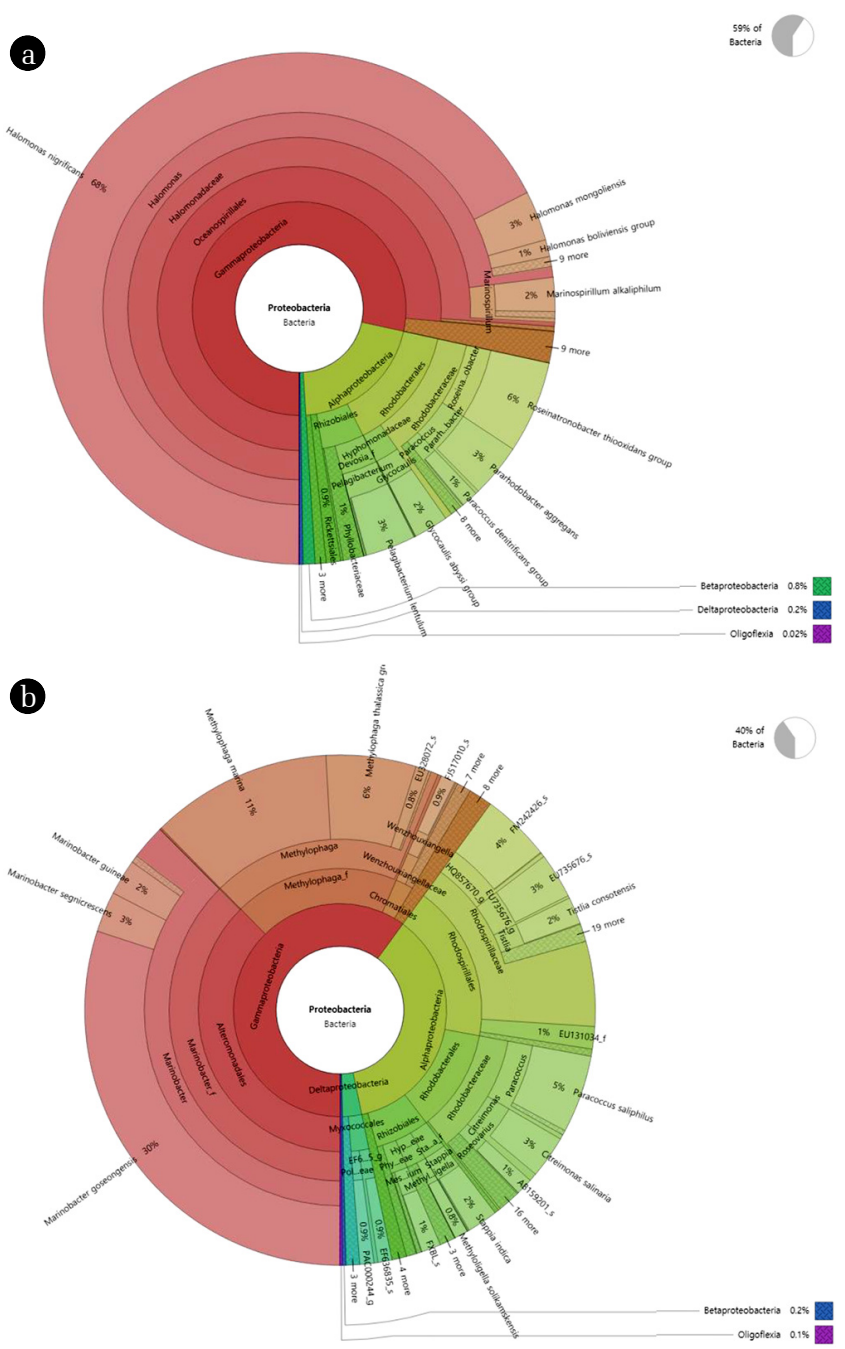

Fig. 6. Results of microbial communities using dynamic pie chart (Krona)((a): initial, (b): end) 
There was a reduction in the proportion of Bacteroidetes, Planctomycetes, Firmicutes, Verrucomicrobia, and Tenericutes. Bacteroidetes decreased from $26.53 \%$ to $4.03 \%$, and are typically found in various wastewater treatment systems, some of which have halophilic characteristics [44]. Planctomycetes, known as aerobic chemo heterotrophs, decreased slightly from $1.50 \%$ to $1.26 \%$; these are mainly found in chemical wastewater treatment [52, 53]. It is estimated that they can grow in halophilic and thermophilic environments. Firmicutes, Verrucomicrobia, and Tenericutes decreased from $5.48 \%, 2.16 \%$, and $0.98 \%$ to $0.31 \%, 0.05 \%$, and $0.01 \%$, respectively. Firmicutes are mainly found in the anaerobic digestion process [54], and Verrucomicrobia has a hydrocarbon hydrolase [55]. They seem to be difficult to grow under the wastewater treatment environment of this study. Altough Tenericutes are also found in various wastewater treatment systems, they exist at a low proportion [56-58] and as such, their contribution is expected to be low.

Fig. 6 shows the pyrosequencing results of Proteobacteria using a dynamic pie chart (Krona) ((a): initial, (b): end). We investigated the Proteobacteria genus to identify microbial characteristics. Halomonas spp. was present in the highest proportion (43.26\%) in (a), and has been reported to grow under highly saline conditions, contributing to the treatment of saline wastewater [59]. Though some Alphaproteobacteria, such as Roseinatronobacter spp. (3.45\%), Pararhodobacter spp. (2.31\%), and Glycocaulis spp. $(1.30 \%)$, have been found to grow in highly saline environments [60-62], they were not found in (b). Similarly, certain Gammaproteobacteria such as Marinospirillum spp., Aliidiomarina spp., and Alcanivorax spp. are known to be capable of treating highly saline wastewater or soil [63-65]. However, with the exception of Halomonas spp. (0.11\%), they were not observed in (b). Marinobacter spp. and Methylophaga spp. constituted $15.12 \%$ and $7.51 \%$ of the microbial community, respectively, unlike the well-known halophilic microorganisms, Gammaproteobacteria [6668]. In several studies, the dominant microorganisms in saline wastewater were Halomonas spp., Paenibacillus spp., and Marinobacter spp. [69-72]. We confirmed that Marinobacter spp. and Methylophaga spp. were dominant and are highly biodegradable in a saline environment. Although the seed sludge was dominated by Halomonas spp. growing in high salinity, changes in microbial species appeared due to the wastewater containing methyl groups. Therefore, we estimated that Marinobacter spp. and Methylophaga spp. was dominated by influent. The genera of the sample in the initial and end phases were 297 and 493, respectively, indicating that microbial communities were diverse in the end phase. This may be regarded as an increase in microbial diversity by operating.

\section{Conclusions}

This study biologically removed the organic matter from highly saline MC wastewater and observed microbial community changes used for biological treatment. The removal efficiency of COD in biological treatment increased from $80.4 \%$ to $93.5 \%$, and removal efficiency was improved by the addition of nutrients such as nitrogen and phosphorus to the wastewater. In this case, the ratio of $\mathrm{C}: \mathrm{N}: \mathrm{P}$ was 240:1.3:1. Although the energy and cost consumption in this study was minimal due to the lack of a physicochemical treatment process, it has a limitation requiring the addition of nutrients for high removal efficiency. However, mixing with high concentrations of industrial or municipal wastewater instead of nutrient-deficient ECH wastewater may resolve this requirement to add chemicals, also achieve scale-up.

The sludge was granulated because of the highly saline conditions and the presence of filamentous bacteria. The microbial community in the sludge was dominated by Proteobacteria ((a): 59.23\%, (b): $40.30 \%)$ in the initial and end phases. There was an increase in the ratio of Chloroflexi ((a): 0.36\%, (b): $26.24 \%$ ) and Actinobacteria ((a): $0.54 \%$, (b): 16.63\%), both of which are filamentous bacteria. Proteobacteria was the dominant Halomomas spp. (43.26\%), a halophilic microorganism, in (a), whereas Marinobacter spp. (15.12\%) and Methylophaga spp. (7.51\%) were dominant in (b). In this study, Marinobacter spp. and Methylophaga spp. were dominant, which differs from the results of previous studies whereas Halomonas spp. was dominant in the biological treatment of saline water [73, 74]. Therefore, we expected Marinobacter spp. and Methylophaga spp. to contribute to the biological treatment of MC wastewater.

This study revealed that Marinobacter spp. and Methylophaga spp. contribute to the treatment of MC wastewater, and confirmed that the addition of nutrients is necessary. Through, this study provided information on MC wastewater treatment that was not previously studied, and contributed to the development of industrial wastewater treatment.

\section{Acknowledgment}

This subject is supported by Korea Ministry of Environment as "Global Top Project" (Project No.:2016002190006).

\section{Author Contributions}

G.S.J. (M.S. student) conducted all the experiments and wrote the manuscript. S.W.H. (Ph.D. student) conducted all the experiments and revised the manuscript. H.G.K. (Ph.D.) revised the manuscript. Z.L.P. (Professor) revised the manuscript. D.H.A. (Professor) revised the manuscript.

\section{References}

1. Hirrien M, Desbrières J, Rinaudo M. Physical properties of methylcelluloses in relation with the conditions for cellulose modification. Carbohydr. Polym. 1996;31:243-252.

2. Dicastillo CL, Bustos F, Guarda A, Galotto MJ. Cross-linked methyl cellulose films with murta fruit extract for antioxidant and antimicrobial active food packaging. Food Hydrocoll. 2016;60:335-344.

3. Lee JY. Relationship between rheological behavior and electrospinnability of methylcellulose and its application for enzyme immobilization [dissertation]. Seoul: Seoul National University; 2016.

4. Kamitakahara H, Nakatsubo F, Klemm D. Block co-oligomers 
of tri-O-methylated and unmodified cello-oligosaccharides as model compounds for methylcellulose and its dissolution/gelation behavior. Cellulose 2006;13:375-392.

5. Kamitakahara H, Nakatsubo F, Klemm D. New class of carbohydrate-based nonionic surfactants: diblock co-oligomers of tri-O-methylated and unmodified cello-oligosaccharides. Cellulose 2007;14:513-528.

6. Han JH. Innovations in food packaging. 2nd ed. New York: Academic Press; 2014. p. 213-255.

7. He H, Chen Y, Li X, Cheng Y, Yang C, Zeng G. Influence of salinity on microorganisms in activated sludge processes: a review. Int. Biodeterior. Biodegradation 2017;119:520-527.

8. Hong J, Li W, Lin B, Zhan M, Liu C, Chen BY. Deciphering the effect of salinity on the performance of submerged membrane bioreactor for aquaculture of bacterial community. Desalination 2013;316:23-30.

9. Rene ER, Kim SJ, Park HS. Effect of COD/N ratio and salinity on the performance of sequencing batch reactors. Bioresour. Technol. 2008;99:839-846.

10. Chowdhury P, Viraraghavan T, Srinivasan A. Biological treatment processes for fish processing wastewater-A review. Bioresour. Technol. 2010;101:439-449.

11. Lofrano G, Meriç S, Zengin GE, Orhon D. Chemical and biological treatment technologies for leather tannery chemicals and wastewaters: a review. Sci. Total Environ. 2013;461:265-281.

12. Lefebvre O, Moletta R. Treatment of organic pollution in industrial saline wastewater: a literature review. Water Res. 2006;40:3671-3682.

13. Kargi F, Dinçer AR. Use of halophilic bacteria in biological treatment of saline wastewater by fed-batch operation. Water Environ. Res. 2000;72:170-174.

14. Kim YB. The application of mecellose wastewater as aternative external carbon for BNR process [dissertation]. Pusan: Pusan National University; 2004.

15. Goswami S, Mazumder D. Treatability study of carbxyl methylcellulose manufacturing wastewater by physico-chemical methods. Indian J. Environ. Prot. 2018;38:533-542.

16. Yin L, Wang J, Chen F. Method for treating waste liquid of cellulose ether production. China Patent. 2005. CN1594113A

17. Rao PH, Zhang WQ, Yao W, et al. Chemical compounds recovery in carboxymethyl cellulose wastewater treatment. Kem. Ind. 2015;64:247-254.

18. Du F, Tang H. Processing method of salty wastewater in cellulose ether production. China Patent. 2012. CN102344225A

19. Gutiérrez-Guerra R, Segovia-Hernández JG, Hernández S. Reducing energy consumption and CO2 emissions in extractive distillation. Chem. Eng. Res. Des. 2009;87:145-152.

20. Jorfi S, Alavi S, Jaafarzadeh N, Ghanbari F, Ahmadi M. COD removal from high salinity petrochemical wastewater using photo-assisted peroxi-coagulation. Chem. Biochem. Eng. Q. 2018;32:229-238.

21. Qin L, Liu Q, Meng Q, et al. Anoxic oscillating MBR for photosynthetic bacteria harvesting and high salinity wastewater treatment. Bioresour. Technol. 2017;224:69-77.

22. Zinatloo-Ajabshir S, Morassaei MS, Amiri O, Salavati-Niasari M. Green synthesis of dysprosium stannate nanoparticles using ficus carica extract as photocatalyst for the degradation of organ- ic pollutants under visible irradiation. Ceram. Int. 2020;46: 6095-6107.

23. Fan J, Zhang J, Zhang C, Ren L, Shi Q. Adsorption of 2, 4, 6-trichlorophenol from aqueous solution onto activated carbon derived from loosestrife. Desalination 2011;267:139-146.

24. Mohan SV, Babu VL, Bhaskar YV, Sarma P. Influence of recirculation on the performance of anaerobic sequencing batch biofilm reactor (AnSBBR) treating hypersaline composite chemical wastewater. Bioresour. Technol. 2007;98:1373-1379

25. Jang D, Hwang Y, Shin H, Lee W. Effects of salinity on the characteristics of biomass and membrane fouling in membrane bioreactors. Bioresour. Technol. 2013;141:50-56.

26. Wang Z, Wu Z. A review of membrane fouling in MBRs: characteristics and role of sludge cake formed on membrane surfaces. Sep. Sci. Technol. 2009;44:3571-3596.

27. Chun J, Lee J, Jung Y, et al. EzTaxon: a web-based tool for the identification of prokaryotes based on 16S ribosomal RNA gene sequences. Int. J. Syst. Evol. Microbiol. 2007;57:2259-2261.

28. Chun J, Kim KY, Lee J, Choi Y. The analysis of oral microbial communities of wild-type and toll-like receptor 2-deficient mice using a 454 GS FLX Titanium pyrosequencer. BMC Microbiol. 2010;10:101.

29. APHA (American Public Health Association). Standard methods for the examination of water and wastewater. Washington D.C.:APHA; 2005.

30. Belkin S, Brenner A, Abeliovich A. Biological treatment of a high salinity chemical industrial wastewater. Water Sci. Technol. 1993;27:105-112.

31. Driscoll T, Kartik J. Industrial wastewater management, treatment and disposal. WEF Manual of Practice No. FD-3rd. New York: Mcgraw-Hill; 2008. p. 474-489.

32. Metcalf L, Eddy HP, Tchobanoglous G. Wastewater engineering: treatment, disposal, and reuse. New York: McGraw-Hill; 2003.

33. Ammary BY. Nutrients requirements in biological industrial wastewater treatment. Afr. J. Biotechnol. 2004;3:236-238.

34. Friha I, Karray F, Feki F, Jlaiel L, Sayadi S. Treatment of cosmetic industry wastewater by submerged membrane bioreactor with consideration of microbial community dynamics. Int. Biodeterior. Biodegradation 2014;88:125-133.

35. Rosman NH, Anuar AN, Othman I, et al. Cultivation of aerobic granular sludge for rubber wastewater treatment. Bioresour. Technol. 2013;129:620-623.

36. Yae J, Ryu J, Tuyen NV, et al. An aerobic granular sludge process for treating low carbon/nitrogen ratio sewage. Environ. Eng. Res. 2018;24:238-245

37. Wang Z, Gao M, She Z, et al. Effects of salinity on performance, extracellular polymeric substances and microbial community of an aerobic granular sequencing batch reactor. Separ. Purif. Technol 2015;144:223-231.

38. Zhu L, Zhou J, Lv M, Yu H, Zhao H, Xu X. Specific component comparison of extracellular polymeric substances (EPS) in flocs and granular sludge using EEM and SDS-PAGE. Chemosphere 2015;121:26-32.

39. Corsino SF, Capodici M, Torregrossa M, Viviani G. Fate of aerobic granular sludge in the long-term: the role of EPSs on the clogging of granular sludge porosity. J. Environ. Manage. 2016;183:541-550. 
40. Jiang H, Tay J, Liu Y, Tay ST. $\mathrm{Ca}^{+2}$ augmentation for enhancement of aerobically grown microbial granules in sludge blanket reactors. Biotechnol. Lett. 2003;25:95-99

41. Corsino SF, Capodici M, Torregrossa M, Viviani G. Physical properties and extracellular polymeric substances pattern of aerobic granular sludge treating hypersaline wastewater. Bioresour. Technol. 2017;229:152-159.

42. Kim H, Ahn D. The effects of high salinity on nitrogen removal and the formation characteristics of aerobic granular sludge. Environ. Eng. Res. 2020;25(5):659-667.

43. Corsino SF, Capodici M, Pippo FD, Tandoi V, Torregrossa M. Comparison between kinetics of autochthonous marine bacteria in activated sludge and granular sludge systems at different salinity and SRTs. Water Res. 2019;148:425-437.

44. Calderón K, Martín-Pascual J, Poyatos JM, Rodelas B, González-Martínez A, González-López J. Comparative analysis of the bacterial diversity in a lab-scale moving bed biofilm reactor (MBBR) applied to treat urban wastewater under different operational conditions. Bioresour. Technol. 2012;121:119-126.

45. Zhang X, Li J, Yu Y, Xu R, Wu Z. Biofilm characteristics in natural ventilation trickling filters (NVTFs) for municipal wastewater treatment: Comparison of three kinds of biofilm carriers. Biochem. Eng. J. 2016;106:87-96.

46. Hanada S. The phylum chloroflexi, the family chloroflexaceae, and the related phototrophic families oscillochloridaceae and roseiflexaceae. The Prokaryotes. Berlin: Spinger; 2014. p. 515-532.

47. Lerner PI. Nocardiosis. Clin. Infect. Dis. 1996;22:891-903.

48. Liu Y, Tay J. The essential role of hydrodynamic shear force in the formation of biofilm and granular sludge. Water Res. 2002;36:1653-1665.

49. Gao DW, Wen ZD. Phthalate esters in the environment: A critical review of their occurrence, biodegradation, and removal during wastewater treatment processes. Sci. Total Environ. 2016;41: 986-1001.

50. Olapade OA. Bacterial Community Composition and Diversity along the Southern Coastlines of the Atlantic Ocean in Cape Town, South Africa. bioRxiv 2020, doi: https://doi.org/10.1101/ 2020.02.27.969030

51. Munoz R, Rosselló-Móra R, Amann R. Revised phylogeny of Bacteroidetes and proposal of sixteen new taxa and two new combinations including Rhodothermaeota phyl. nov. Syst. Appl. Microbiol. 2016;39:281-296.

52. Yang Q, Jia Z, Liu R, Chen J. Molecular diversity and anammox activity of novel planctomycete-like bacteria in the wastewater treatment system of a full-scale alcohol manufacturing plant. Process Biochem. 2007;42:180-187.

53. Chouari R, Le Paslier D, Daegelen P, Ginestet P, Weissenbach J, Sghir A. Molecular evidence for novel planctomycete diversity in a municipal wastewater treatment plant. Appl. Environ. Microbiol. 2003;69:7354-7363.

54. Chen S, Cheng H, Wyckoff KN, He Q. Linkages of Firmicutes and Bacteroidetes populations to methanogenic process performance. J. Ind. Microbiol. Biotechnol. 2016;43:771-781.

55. Martinez-Garcia M, Brazel DM, Swan BK, et al. Capturing single cell genomes of active polysaccharide degraders: an unexpected contribution of Verrucomicrobia. PLoS ONE 2012;7 (4):e35314.
56. Storey S, Chualain DN, Doyle O, Clipson N, Doyle E. Comparison of bacterial succession in green waste composts amended with inorganic fertiliser and wastewater treatment plant sludge. Bioresour. Technol.2015;179:71-77.

57. Ferrera I, Sanchez O. Insights into microbial diversity in wastewater treatment systems: How far have we come?. Biotechnol. Adv. 2016;34:790-802.

58. Yang Y, Yu K, Xia Y, et al. Metagenomic analysis of sludge from full-scale anaerobic digesters operated in municipal wastewater treatment plants. Appl. Microbiol. Biotechnol. 2014;98: 5709-5718.

59. Jung R, Yang H, Lee J, Kim Y. A novel halophilic Halomonas sp. having an excellent digestive effect of organic material, a soil conditioner for the reclaimed land using said strain and a method for plant growth-promoting thereof. Republic of Korea patent application. 2008.

60. Sorokin DY, Tourova T, Kuznetsov B, Bryantseva I, Gorlenko V. Roseinatronobacter thiooxidans gen. nov., sp. nov., a new alkaliphilic aerobic bacteriochlorophylla - containing bacterium isolated from a soda lake. Microbiology 2000;69:75-82.

61. Foesel BU, Drake HL, Schramm A. Defluviimonas denitrificans gen. nov., sp. nov., and Pararhodobacter aggregans gen. nov., sp. nov., non-phototrophic Rhodobacteraceae from the biofilter of a marine aquaculture. Syst. Appl. Microbiol. 2011;34:498-502.

62. Lv X, Xie B, Cai M, et al. Glycocaulis albus sp. nov., a moderately halophilic dimorphic prosthecate bacterium isolated from petroleum-contaminated saline soil. Int. J. Syst. Evol. Microbiol. 2014;64:3181-3187

63. Zhang W, Xue Y, Ma Y, Grant WD, Ventosa A, Zhou P. Marinospirillum alkaliphilum sp. nov., a new alkaliphilic helical bacterium from Haoji soda lake in Inner Mongolia Autonomous Region of China. Extremophiles 2002;6:33-37.

64. Xu L, Sun J, Wang L, et al. Aliidiomarina soli sp. nov., isolated from saline-alkaline soil. Int. J. Syst. Evol. Microbiol. 2017;67: 724-728.

65. Dastgheib SMM, Amoozegar MA, Khajeh K, Ventosa A. A halotolerant Alcanivorax sp. strain with potential application in saline soil remediation. Appl. Microbiol. Biotechnol. 2011;90: 305-312.

66. Gauthier MJ, Lafay B, Christen R, et al. Marinobacter hydrocarbonoclasticus gen. nov., sp. nov., a new, extremely halotolerant, hydrocarbon-degrading marine bacterium. Int. J. Syst. Evol. Microbiol. 1992;42:568-576

67. Yoshie S, Noda N, Tsuneda S, Hirata A, Inamori Y. Salinity decreases nitrite reductase gene diversity in denitrifying bacteria of wastewater treatment systems. Appl. Environ. Microbiol. 2004;70:3152-3157.

68. Surakasi VP, Antony CP, Sharma S, Patole MS, Shouche YS. Temporal bacterial diversity and detection of putative methanotrophs in surface mats of Lonar crater lake. J. Basic Microbiol. 2010;50:465-474.

69. Bonfá MRL, Grossman MJ, Piubeli F, Mellado E, Durrant LR. Phenol degradation by halophilic bacteria isolated from hypersaline environments. Biodegradation 2013;24:699-709.

70. Dosta J, Nieto J, Vila J, Grifoll M, Mata-Álvarez J. Phenol removal from hypersaline wastewaters in a membrane biological reactor (MBR): operation and microbiological characterisation. 
Bioresour. Technol. 2011;102:4013-4020.

71. Lee JW, Kim BH, Park YS, Song YC, Koh SC. Microbial community analysis in the wastewater treatment of hypersaline-wastewater. Korean J. Microbiol. Biotechnol. 2014;42:
377-385.

72. Berlendis S, Cayol JL, Verhé F, et al. First evidence of aerobic biodegradation of BTEX compounds by pure cultures of Marinobacter. Appl. Biochem. Biotechnol. 2010;160:1992-1999. 